\title{
A Fuzzy Based Efficient Load Flow Analysis
}

\author{
Jaydeep Chakravorty, Sandeep Chakravorty, Smarajit Ghosh
}

\begin{abstract}
Load flow calculation is one of the most basic problems in power engineering. The repetitive solution of a large set of linear equations in load flow problem is one of the most time consuming parts of power systems simulations. Load flows are calculated using the traditional method such as Gauss Seidel or Newton Raphson methods. Gauss Seidel algorithm is an iterative numerical procedure and in this method the number of iteration depends on the acceleration factor $(\alpha)$. Here we attempt to choose the acceleration factor $(\alpha)$ using fuzzy logic technique so as to minimize the number of iteration and get the result in minimum required time. Comparison of the method with traditional method has been shown in the paper which proves the validity of the result. The paper shows as to how the application of Fuzzy technique in choosing an appropriate acceleration factor reduces the number of iteration and helps in obtaing the solution at a faster rate with optimum number of iterationThe simulation in carried out in MATLAB environment.
\end{abstract}

Index Terms-Load flow, Fuzzy logic technique. Gauss Seidel Method

\section{INTRODUCTION}

With the growing concern for maintaining stable voltage operation within the network, many critical issues on voltage stability related studies have been raised in the area of Power system research. Problems regarding steady state and transient analysis of power systems mainly require iterative solutions of large sets of equations representing system components [1]. The load flow calculation is one of the most basic problems in power engineering [2-8]. The repetitive solution of a large set of linear equations in the load flow problem is one of the most time consuming parts of power system simulations.

Parallel and vector processing [9-11], have been adopted to solve this problem in recent years. Sparse vector and refactorisation methods [12-15] have also been widely used in research on vectors of sparse linear equations. The main disadvantage of all these sophisticated methods is the large number of calculations which are needed on account of factorization, refactorisation and computations on the jacobian matrix.

A straight forward implementation of these methods becomes inefficient when large scale networks exist, resulting in additional memory requirement and computing

Manuscript received April 6, 2009.

Jaydeep Chakravorty is with Sikkim Manipal Institute of Technology under Sikkim Manipal University, Department of Electrical \& Electronics Engineering,Maitar,Rangpo,EsatSikkim,India

Sandeep Chakravorty is with Sikkim Manipal Institute of Technology under Sikkim Manipal University, Department of Electrical \& Electronics Engineering,Maitar,Rangpo,EsatSikkim,India

Smarajit Ghosh is with the Thapar University, Department of Electrical \& Instrumentation Engineering,Patiala,Punjab-147004, India time.

Traditionally, load flows are calculated using the Gauss Seidel and Optimal Load Flow (or Newton Raphson) methods. In [16 2], Wu et al proposed a new technique that took advantage of the radial structure of most power distribution systems. Wu et al called their method, DistFlow and claimed it was computationally superior to the other two methods because of the simplified method of calculating the optimal load flow. The DistFlow method is computationally superior to the other two methods because it does not require the admittance matrix calculation to optimize the distribution system.

This paper aims at the speed of optimization from the point of view of iteration. In this paper we have shown as to how the number of iteration is dependent on acceleration factor $(\alpha)$ and how a choice of correct acceleration factor $(\alpha)$ gives the optimum result in minimum iteration applying Gauss Seidel Method.

The Gauss Seidel algorithm is an iterative numerical procedure which attempts to find a solution to the system of linear equations by repeatedly solving the linear system until the iteration solution is within a predetermined acceptable bound of error. It is a robust and reliable load flow method that provides convergence to extremely complex power systems. The number of iteration for the solution to be within a predetermined acceptable bound of error depends upon the acceleration factor $(\alpha)$. By choosing the correct value of ' $\alpha$ ' we can achieve the optimum solution in minimum number of iterations.

In this paper we have tried to choose optimum values of acceleration factor $(\alpha)$ so as to achieve the solution in minimum number of iterations using Fuzzy technique.

\section{Conventional Method}

The Gauss-Seidel method is one of the simplest iterative methods known. It is in use since early days of digital computer methods of analysis. It has advantages like it is simple, computation cost is less. It is a robust and reliable load flow method that provides convergence to extremely complex power flow systems [22].

In Gauss-Seidel method for an $\mathrm{n}$ bus system the bus voltages are calculated by the formula

$$
V_{i}^{r+1}=\frac{1}{Y_{i i}}\left[\begin{array}{c}
I_{i}^{r}-\sum_{\substack{j=1 \\
j \neq i}}^{n} Y_{i j} V_{j}^{r}
\end{array}\right]
$$

Where the subscript $\mathrm{i}$ denotes the bus number and the superscript $r$ denotes the iteration number, $\mathrm{Y}$ is the admittance matrix of the system. I is the bus current. 
$\mathrm{V}$ is the bus voltage.

Again if for each bus $i$ the complex power $S_{i}$ is known then the bus current can be calculated as

$I_{i}^{r}=\frac{S_{i}^{*}}{\left(V_{i}^{k}\right)^{*}}=\frac{P_{i}-j Q_{i}}{\left(V_{i}^{k}\right)^{*}}$

Where $\mathrm{P}$ and $\mathrm{Q}$ are the real and the reactive power of the bus respectively and $\mathrm{V}^{*}$ is the complex conjugate of the bus voltage. Substituting equation (2) in equation (1) we get

$$
V_{i}^{r+1}=\frac{1}{Y_{i i}}\left[\frac{P_{i}-j Q_{i}}{\left(V_{i}^{k}\right)^{*}}-\sum_{\substack{j=1 \\ j \neq i}}^{n} Y_{i j} V_{j}^{r}\right]
$$

This iteration in continued until the iteration solution in within a predetermined acceptable bound of error. Or in other words, the iteration stops if

$\left|V_{i}^{r+1}-V_{i}^{r}\right| \leq \varepsilon$

Where $\varepsilon$ is the tolerance condition.

The rate of convergence of Gauss-Siedel method can be increased by applying an acceleration factor $\alpha$ at the end of each iteration. That is after obtaining the bus voltage $V_{i}^{k+1}$ the correction factor is calculated as follows

$$
\begin{aligned}
& \Delta V_{i}^{r+1}=\alpha\left(V_{i}^{r+1}-V_{i}^{r}\right) \\
& \text { and } V_{i}^{r+1}(a c c)=V_{i}^{r}+\Delta V_{i}^{r+1}
\end{aligned}
$$

The value of voltage obtained in equation (6) is the new voltage of bus $i$ after the $(r+1)^{\text {th }}$ iteration. In equation (5), $\alpha$ is the acceleration factor. Usually satisfactory range of acceleration factor is with in 1.1 to 1.9 . Proper selection of acceleration factor can reduce the number of iteration to a greater extent.

In the paper two different bus systems has been taken

i) Five bus architecture

ii) Three bus architecture

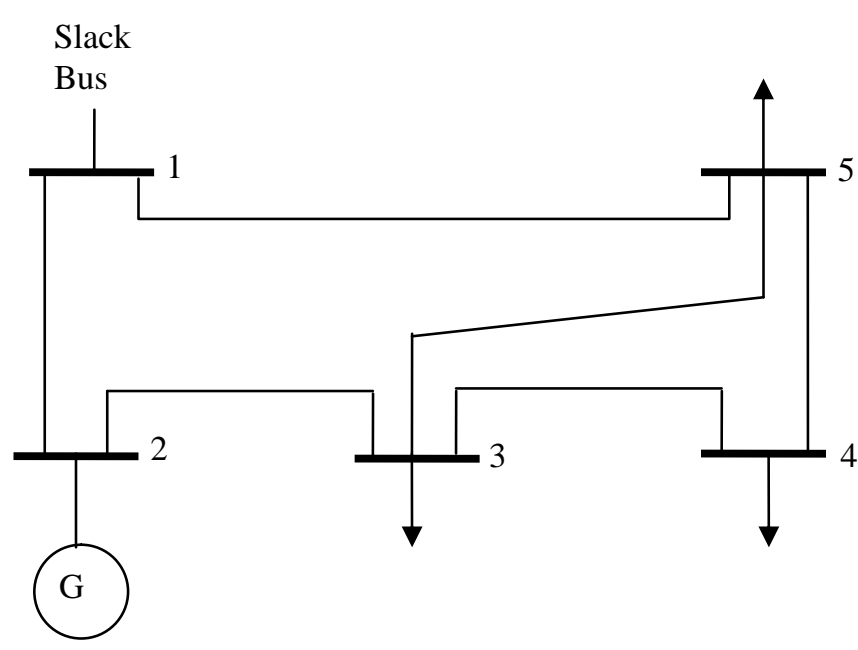

Figure 1: Showing the five bus architecture.

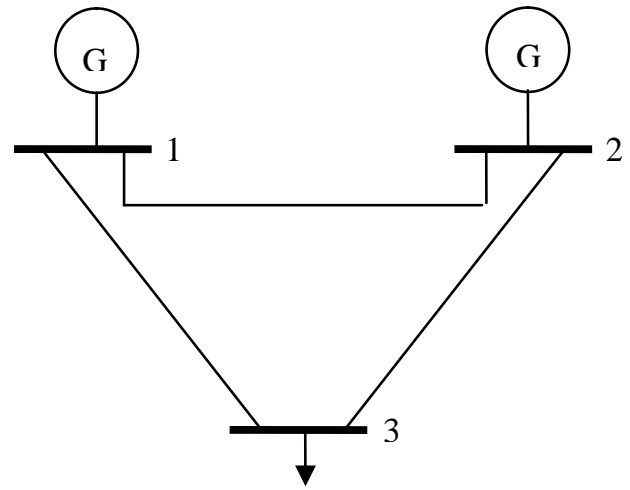

Figure 2: Showing the three bus architecture.

\begin{tabular}{|c|c|c|c|}
\hline \multicolumn{2}{|c|}{$\begin{array}{l}\text { Bus } \\
\text { Code }\end{array}$} & \multirow[b]{2}{*}{$\begin{array}{l}\text { Impedance } \\
\left(\mathrm{Z}_{\mathrm{pq}}\right)\end{array}$} & \multirow[b]{2}{*}{$\begin{array}{l}\text { Line Charge } \\
\left(y_{p q}^{\prime}\right.\end{array}$} \\
\hline $\mathbf{P}$ & $\mathbf{q}$ & & \\
\hline 1 & 2 & $0.02+\mathrm{j} 0.04$ & j0.02 \\
\hline 2 & 3 & $0.04+\mathrm{j} 0.2$ & j0.02 \\
\hline 3 & 5 & $0.15+j 0.4$ & j0.02 \\
\hline 3 & 4 & $0.02+\mathrm{j} 0.06$ & j0.02 \\
\hline 4 & 5 & $0.02+\mathrm{j} 0.04$ & $\mathrm{j} 0.02$ \\
\hline 1 & 5 & $0.08+\mathrm{j} 0.2$ & j0.02 \\
\hline
\end{tabular}

The input data for five bus system has been shown in Table 1

\begin{tabular}{|c|c|c|c|c|}
\hline & \multicolumn{2}{|c|}{ GENERATION } & \multicolumn{2}{|c|}{ LOAD } \\
\hline $\begin{array}{l}\text { Bus } \\
\text { Code } \\
\text { (p) } \\
\end{array}$ & MW & MVAR & MW & MVAR \\
\hline $\begin{array}{l}1 \\
\text { (Slack } \\
\text { Bus) }\end{array}$ & 0 & 0 & 0 & 0 \\
\hline 2 & 50 & 25 & 15 & 10 \\
\hline 3 & 0 & 0 & 45 & 20 \\
\hline 4 & 0 & 0 & 40 & 15 \\
\hline 5 & 0 & 0 & 50 & 25 \\
\hline
\end{tabular}
and Table 2.

The result obtained after solving the five bus problems by conventional Gauss-Seidel method has been summarized in Table 3 to Table 5. In Table 3 the bus voltages after the calculation has been tabulated. In Table 4, the line flow between the buses has been tabulated. And in Table 5 the bus power has been tabulated.

\begin{tabular}{|l|l|}
\hline Tus Number & Voltage \\
\hline 1 & $1+\mathrm{j} 0$ \\
\hline 2 & $0.98848-\mathrm{j} 0.01334$ \\
\hline 3 & $0.91008-\mathrm{j} 0.15116$ \\
\hline 4 & $0.89983-\mathrm{j} 0.16208$ \\
\hline 5 & $0.90409-\mathrm{j} 0.15201$ \\
\hline
\end{tabular}

Table 4: Line Flow

\begin{tabular}{|l|l|}
\hline Bus (p-q) & Complex power \\
\hline $1-2$ & $-0.38200579793936+\mathrm{j} 0.11709240009220 \mathrm{i}$ \\
\hline $1-5$ & $-0.82057568148569+\mathrm{j} 0.17131216239168$ \\
\hline $2-1$ & $0.37889869066306-\mathrm{j} 0.07133292380355$ \\
\hline
\end{tabular}




\begin{tabular}{|l|l|}
\hline $2-3$ & $-0.73275987943915+\mathrm{j} 0.25125749568291$ \\
\hline $3-2$ & $0.70858511592859-\mathrm{j} 0.09381643325567$ \\
\hline $3-4$ & $-0.21064103233395+\mathrm{j} 0.07474811679518$ \\
\hline $3-5$ & $-0.00804703542336+\mathrm{j} 0.02731334379027$ \\
\hline $4-3$ & $0.20952008301513-\mathrm{j} 0.03764387431131$ \\
\hline $4-5$ & $0.21703429101772+\mathrm{j} 0.07025612732712$ \\
\hline $5-1$ & $0.76487649592302+\mathrm{j} 0.00474557258763 \mathrm{i}$ \\
\hline $5-3$ & $0.00801695663375+\mathrm{j} 0.00659862052638$ \\
\hline $5-4$ & $-0.21822978916698-\mathrm{j} 0.03433594856692$ \\
\hline
\end{tabular}

Table 5: Bus Power

\begin{tabular}{|l|l|l|}
\hline \multirow{2}{*}{$\begin{array}{l}\text { Bus } \\
\text { No. }\end{array}$} & Power \\
\cline { 2 - 3 } & Real & Reactive \\
\hline 1 & -1.20258147942505 & 0.28840456248389 \\
\hline 2 & -0.35386118877608 & 0.17992457187936 \\
\hline 3 & 0.48989704817128 & 0.00824502732978 \\
\hline 4 & 0.42655437403285 & 0.03261225301581 \\
\hline 5 & 0.55466366338979 & -0.0229917554529 \\
\hline
\end{tabular}

Similarly the input data for three bus system has been shown in Table 6 and Table 7. The result obtained after solving the three bus problems by conventional Gauss-Seidel method has been summarized in Table 8 to Table 10. In Table 8 the bus voltages after the calculation has been tabulated. In Table 9, the line flow between the buses has been tabulated. And in Table 10 the bus power has been tabulated.

Table 6: Bus impedances for 3 bus system

\begin{tabular}{|c|c|c|c|c|c|}
\hline \multicolumn{2}{|c|}{$\begin{array}{l}\text { Bus } \\
\text { Code }\end{array}$} & \multirow{2}{*}{\multicolumn{2}{|c|}{$\begin{array}{l}\text { Impedance }\left(\mathbf{Z}_{\mathrm{pq}}\right) \\
\text { (p.u.) }\end{array}$}} & \multirow{2}{*}{\multicolumn{2}{|c|}{$\begin{array}{l}\text { Line Charge } \\
\left(y_{p q}^{\prime} / 2\right)\end{array}$}} \\
\hline $\mathbf{P}$ & $\mathbf{q}$ & & & & \\
\hline 1 & 2 & \multicolumn{2}{|c|}{$0.002+\mathrm{j} 0.002$} & \multicolumn{2}{|l|}{ j0.02 } \\
\hline 1 & 3 & \multicolumn{2}{|c|}{$0.002+\mathrm{j} 0.002$} & \multicolumn{2}{|l|}{ j0.02 } \\
\hline \multirow{2}{*}{\multicolumn{2}{|c|}{3}} & \multicolumn{2}{|c|}{$0.002+\mathrm{j} 0.002$} & \multicolumn{2}{|l|}{ j0.02 } \\
\hline & & \multicolumn{2}{|c|}{ GENERATION } & \multicolumn{2}{|c|}{ LOAD } \\
\hline \multicolumn{2}{|c|}{$\begin{array}{l}\text { Bus } \\
\text { Code } \\
\text { (p) }\end{array}$} & MW & MVAR & MW & MVAR \\
\hline \multicolumn{2}{|l|}{1} & 150 & 20 & & \\
\hline \multirow{2}{*}{\multicolumn{2}{|c|}{$\frac{2}{3}$}} & 50 & 10 & & \\
\hline & & & & 200 & \\
\hline
\end{tabular}

Table 7: Load data for 5 bus system

\begin{tabular}{|l|lr|}
\hline $\begin{array}{l}\text { Bus } \\
\text { Number }\end{array}$ & Voltage (p.u.) \\
\hline 1 & $1+\mathrm{j} 0$ \\
\hline 2 & 0.99946569428928 & - \\
& $\mathrm{j} 0.00080641189297$ & - \\
\hline 3 & 0.99773331796151 & \\
& $\mathrm{j} 0.00241246724001$ & \\
\hline
\end{tabular}

Table 8: Bus Voltages

\begin{tabular}{|l|ll|}
\hline Bus (p-q) & Complex Power & \\
\hline $1-2$ & -0.33517940092284 & - \\
& j0.04802654556235 & \\
\hline $1-3$ & -1.16978731962464 & \\
& $-\mathrm{j} 0.01644630038213$ & \\
\hline $2-1$ & 0.33494545523943 & + \\
\hline
\end{tabular}

\begin{tabular}{|c|c|c|}
\hline & j0.08823913773298 & \\
\hline $2-3$ & $\begin{array}{l}-0.83418744960992 \\
j 0.05086898041048\end{array}$ & + \\
\hline $3-1$ & $\begin{array}{l}1.16704785821271 \\
\text { j0.05909531366944 }\end{array}$ & + \\
\hline $3-2$ & $\begin{array}{l}0.83279231423023 \\
-\mathrm{j} 0.00958564666819\end{array}$ & \\
\hline
\end{tabular}

\begin{tabular}{|c|c|c|}
\hline \multirow{2}{*}{$\begin{array}{l}\text { Bus } \\
\text { No. }\end{array}$} & \multicolumn{2}{|l|}{ Power } \\
\hline & Real & Reactive \\
\hline 1 & -1.50496672054748 & $-\mathrm{j} 0.06447284594448$ \\
\hline 2 & -0.49924199437048 & j0.13910811814346 \\
\hline 3 & 1.99984017244294 & $\mathrm{j} 0.04950966700125$ \\
\hline
\end{tabular}

\section{Proposed Methodology}

The method proposed in this paper deals with selection of acceleration factor with the help of fuzzy logic concept. Here instead of using an arbitrary acceleration factor for the iteration, we will be using variable acceleration factor. That is the value of the acceleration factor will change after every iteration. The new value of acceleration factor will depend upon the error value obtained in the previous iteration.

A membership functions for error value has been shown in Figure 3 and the membership function for acceleration factor is shown in Figure 4. And the fuzzy rules are shown in Table 12

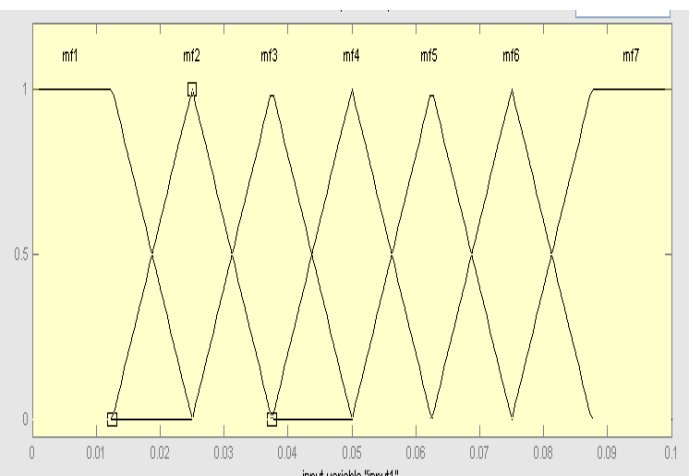

Figure 3: Showing the membership function for error value.

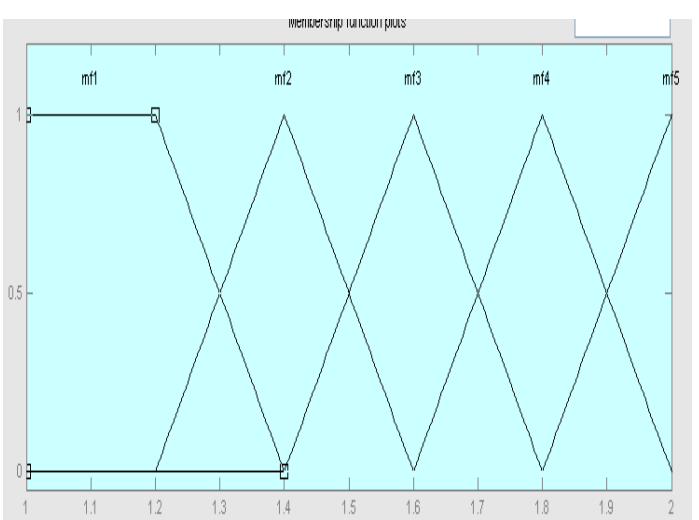

Figure 4: Showing the membership function for acceleration factor.

Table: 12 Fuzzy Rules

\begin{tabular}{|l|}
\hline 1. If (input1 is $\mathrm{mf} 1$ ) then (output1 is mf1) \\
\hline 2. If (input1 is $\mathrm{mf} 1$ ) then (output1 is mf5) \\
\hline 3. If (input1 is $\mathrm{mf} 2$ ) then (output1 is $\mathrm{mf} 4$ ) \\
\hline 4. If (input1 is $\mathrm{mf} 2$ ) then (output1 is $\mathrm{mf} 5$ ) \\
\hline 5. If (input1 is $\mathrm{mf}$ ) then (output1 is $\mathrm{mf}$ ) \\
\hline
\end{tabular}




\begin{tabular}{|l|}
\hline 6. If (input1 is $\mathrm{mf} 3$ ) then (output1 is $\mathrm{mf} 4$ ) \\
\hline 7. If (input1 is $\mathrm{mf} 4$ ) then (output1 is $\mathrm{mf} 4$ ) \\
\hline 8. If (input1 is $\mathrm{mf} 4$ ) then (output1 is $\mathrm{mf} 3$ ) \\
\hline 9. If (input1 is $\mathrm{mf} 5$ ) then (output1 is $\mathrm{mf} 1$ ) \\
\hline 10. If (input1 is $\mathrm{mf} 5$ ) then (output1 is $\mathrm{mf} 4$ ) \\
\hline 11. If (input1 is $\mathrm{mf} 6$ ) then (output1 is $\mathrm{mf} 4$ ) \\
\hline 12. If (input1 is $\mathrm{mf}$ ) then (output1 is $\mathrm{mf}$ ) \\
\hline 13. If (input1 is $\mathrm{mf} 7$ ) then (output1 is $\mathrm{mf5}$ ) \\
\hline 14. If (input1 is $\mathrm{mf} 7$ ) then (output1 is $\mathrm{mf}$ ) \\
\hline
\end{tabular}

Using the fuzzy rules of Table 12, after each iteration, depending on the error obtained a new value of acceleration factor $\alpha$ is calculated. This value of $\alpha$ is used for the next iteration. Note that in this method the range of $\alpha$ has been taken from 1.1 to 1.8. This proposed method when applied to the five bus and three bus systems of Figure 1 and Figure 2, respectively, the number of iteration required was nearly the optimum. This has been summarized in the Table13. More over this new method did not affect the final answer at all.

Table 13: No of iterations in the new proposed method

\begin{tabular}{|l|l|}
\hline BUS & No. of iterations \\
\hline 5 & 17 \\
\hline 3 & 3 \\
\hline
\end{tabular}

Note that in all the calculations the base MVA has been taken as 100MVA. The tolerance value $\varepsilon$ has been taken as 0.001

\section{CASE STUdy}

Effect of acceleration factor on number of iteration for the five and three bus system using conditional method discussed earlier is as shown in the Table 11.

Table 11: Effect of acceleration factor on number of iterations

\begin{tabular}{|l|l|l|}
\hline BUS & Acceleration Factor $(\boldsymbol{\alpha})$ & $\begin{array}{l}\text { No. of } \\
\text { iterations }\end{array}$ \\
\hline \multirow{5}{*}{5} & 1.1 & 30 \\
\cline { 2 - 3 } & 1.2 & 25 \\
\cline { 2 - 3 } & 1.3 & 20 \\
\cline { 2 - 3 } & 1.4 & 17 \\
\cline { 2 - 3 } & 1.5 & 15 \\
\cline { 2 - 3 } & 1.6 & 18 \\
\hline \multirow{5}{*}{3} & 1.7 & 26 \\
\hline \multirow{5}{*}{} & 1.8 & 50 \\
\hline & 1.1 & 3 \\
\cline { 2 - 3 } & 1.2 & 3 \\
\cline { 2 - 3 } & 1.3 & 3 \\
\cline { 2 - 3 } & 1.4 & 3 \\
\cline { 2 - 3 } & 1.5 & 3 \\
\cline { 2 - 3 } & 1.6 & 4 \\
\cline { 2 - 3 } & 1.7 & 4 \\
\cline { 2 - 3 } & 1.8 & 6 \\
\hline
\end{tabular}

For Table 11 we can conclude that if the selection of acceleration factor for Gauss-Seidel method is correct then it can bring convergence in very little iteration.

Using the proposed methodology that is varying the acceleration factor after every iteration using the fuzzy logic concept we get the result as summarized in Table 13 .

From the result of Table 11 and Table 13 we can conclude the method suggested gives optimum iteration and hence the method suggested can give the result of the load flow study in minimum number of iteration.

\section{CONCLUSION}

The result obtained in this paper proves that application fuzzy logic concept to change the acceleration factor after every iteration helps in minimizing the number of iteration. It also proves that by this method we can achieve the result in minimum possible iteration which saves the computation time and improves the efficiency of the method.

\section{DISCUSSION}

In this paper we have assumed that the load bus reactive power is know but it is quite often that the reactive power status at the load bus is not specified. Under such circumstances the reactive power status is to be obtained first before proceeding with the calculation of the load bus voltage.

\section{REFERENCES}

[1] BASSO,A., MINUSSI,C., and PADILHA, D.: 'Fast forward/fast backward substitution on vector computers', IEEE Trans., 1999, PWS-14, (4), pp. 1369-1373.

[2] VLACHOGIANNIS, J.G.: 'Control adjustments in fast decoupled load flow', Electr. Power Syst. Res., 1994, 31, pp.185-194.

[3] CHANG, S.K., and BRANDWAJN, V.: 'Adjusted solutions in fast decoupled load flow', IEEE Trans., 1988, PWS-3, (2), pp.726-733.

[4] CHANG, S.K., and BRANDWAJN, V.: 'Solving the adjustment interactions in fast decoupled load flow', IEEE Trans., 1991, PWS-6, (2). pp.801-805.

[5] GHOSH, S., and DAS, D.: 'Method for load-flow solution of radial distributed networks', IEEE Proc-Gener. Transm. Distrib., 1999, 146, (6), pp.641-648.

[6] RAJICIC, D., and BOSE, A.: 'a modification to the fast decoupled power flow for networks', IEEE Trans., 1988, PWS-3, (2), pp.743-746.

[7] AMERONGEN, R.A.M.: 'A general-purpose version of the fast decoupled load flow', IEEE Trans., 1989, PWS-4, (2), pp.760-770.

[8] BARRAS, J., ALEC, S., PASCHE, C., CHAMOREL, P.A., GERMOND, A.J., and WERRA, D.: Network simplex method applied to AC load flow calculation', IEEE Trans., 1987, PWS-2, (1), pp.197-203.

[9] FUERTE-ESQUIVEL, C., ACHA, E., TAN, S.G., and RICO, J.J.: 'Efficient object oriented power system software for the analysis of large scale networks containing FACTS controlled branches', IEEE Trans., 1998, PWS-13 , (2), pp.464-472.

[10] HAKAVIK, B., and HOLEN, A.T.: 'Power system modeling and sparse matrix operations using object oriented programming', IEEE Trans., 1994, PWS-9, (2), pp.1045-1051.

[11] FOLEY, M., and BOSE, A.: 'Object oriented on line network analysis', IEEE Trans., 1995, PWS-10, (1), pp. 125-132.

[12] TINNEY, W.F., BRANDWAJN, V., and CHAN, S.M.: 'Sparse vector methods', IEEE Trans., 1985, PAS-104, (2), pp.295-301.

[13] ENNS,M.K., TINNEY, W.F., and ALVERADO, F.L.: 'Sparse matrix inverse factors', IEEE Trans., 1990, PWS-5, (2), pp.466-472.

[14] CHAN, S.M., and BRANDWAJN, V.: 'Partial matrix refactorization', IEEE Trans., 1986, PWS-1, (1), pp.193-200.

[15] BAKIRTZIS, A.G., and VLACHOGIANNIS, J.G.: 'Block matrices and their applications in power systems', Electr. Power Syst. Res., 1993, 28, pp. 51-58.

[16] Wu et al, 'Network Reconfiguration in Distribution Systems for Loss Reduction and Load Balancing,' IEEE Trans., Vol.4, No. 2, April 1989.

[17] S. CIVANALR et al, 'Distribution Reconfiguration for Loss Minimization,' IEEE Trans. on Power Delivery, Vol 3, No. 3, 1988, pp.1217-1223. 
[18] D.I. SUN et al, 'Optimal Power Flow by Newton Approach,' IEEE Trans. on Power Apparatus and Systems, Vol. PAS-103, Oct 1984, pp. 2864-2880.

[19] D.G.LUENBERGER, Linear and Non-Linear Programming, Reading, MA: Addison-Wesley Publishing Company, 1984, pp. 295-392, 423-455.

[20] TURAN GONEN, Electric Power Distribution System Engineering, McGraw-Hill Publishing Company, Toronto 1986.

[21] ZADEH,L.A.: 'Outline of a new approach to the analysis of complex systems and decision processes', IEEE Trans., 1973, SMC-3, (1), pp. 28-44.

[22] GILBERT, G.M., BOUCHARD, D.E., and CHIGHANI, A.Y.: 'A comparison of load flow analysys using distflow, Gauss-Seidel and optimal load flow algorithms.' IEEE Trans. 1998. pp. 850-853.

[23] Sandeep Chakravorty and Manish thukral. (2009), "Choosing Distribution Sub Station Location Using Soft Computing Technique", International Conference on Advances in Computing, Communication and Control - 2009 Mumbai. India.

[24] Sandeep Chakravorty and Manish Thukral. (2008), "Using Genetic Algorithm to Determine the Optimum Location of the Sub Station", International Workshop and IEEE EDS Mini Colloquia on NAnometer CMOS Technology (WIMNACT 2008) on Nanoelectronics 6-8 March 2008.

[25] Sandeep Chakravorty, Smarajit Ghosh, "An Improvised Method for Distribution of Loads and Configuration of Distribution Sub Station", International Journal of Engineering Research and Industrial Applications. Ascent Publication.

[26] Sandeep Chakravorty, Smarajit Ghosh, "Fuzzy Based Distribution Planning Technique", Journal of Electrical Engineering.Politehnica Publishing House. 